\title{
Indications and patterns of use of benzodiazepines and opioids in severe interstitial lung disease: a population- based longitudinal study
}

\author{
Jenny Genberg ${ }^{1}$, Joanna M. Davies², Zainab Ahmadi ${ }^{3}$, David Currow ${ }^{4}$, \\ Miriam J. Johnson ${ }^{5}$, Hanan Tanash ${ }^{6}$, Sabrina Bajwah (10) ${ }^{2}$ and Magnus Ekström (10 ${ }^{3}$ \\ Affiliations: ${ }^{1}$ Faculty of Science and Technology, Umeå University, Umeå, Sweden. ${ }^{2}$ Cicely Saunders Institute \\ of Palliative Care, Policy and Rehabilitation, King's College London, London, UK. ${ }^{3}$ Division of Respiratory \\ Medicine and Allergology, Dept of Clinical Sciences, Lund University, Lund, Sweden. ${ }^{4}$ IMPACCT, Faculty of \\ Health, University of Technology Sydney, Ultimo, Australia. ${ }^{5}$ Wolfson Palliative Care Research Centre, Hull \\ York Medical School, University of Hull, Hull, UK. ${ }^{6}$ Dept of Respiratory Medicine and Allergology Malmö, \\ Skåne University Hospital, Lund University, Malmö, Sweden.
}

Correspondence: Magnus Ekström, Dept of Medicine, Blekinge Hospital, 37185 Karlskrona, Sweden. E-mail: pmekstromagmail.com

\section{ABSTRACT}

Background: Despite evidence that opioids might relieve chronic breathlessness, physicians may still be reluctant to prescribe them due to safety concerns. By contrast, benzodiazepine (BDZ) prescribing often seeks to reduce chronic breathlessness despite no evidence of net benefit. Prescribing patterns and indications for these medications in severe interstitial lung disease (ILD) are unknown. Here, our objective was to evaluate the indications, medications and temporal patterns of $\mathrm{BDZ}$ and opioid prescriptions in people with oxygen-dependent ILD.

Methods: This was an observational, population-based, longitudinal study of adults starting long-term oxygen therapy (LTOT) for ILD between 2005 and 2014 in the Swedish National Registry for Respiratory Failure (Swedevox). People dispensed BDZs $(n=2000)$ and opioids $(n=2000)$ from 6 months before start of LTOT throughout follow-up (first of death or study end) were analysed.

Results: Of 1635 included patients, 651 (39.8\%) received BDZs and 710 (43.4\%) received opioids during the study period; $373(22.8 \%)$ patients received both. The most frequently prescribed BDZs and opioids were oxazepam (85.6\%) and oxycodone (28.7\%), respectively. Indications for breathlessness were uncommon for BDZs (1.4\%) and opioids (6.4\%). During the last year of life, opioid indications for breathlessness increased from $2.5 \%$ (12-10 months before death) to $10.2 \%$ in the last 3 months of life ( $p=0.048$ ).

Conclusions: In oxygen-dependent ILD, opioids are rarely prescribed for breathlessness even in the last months of life, when chronic breathlessness often increases in prevalence and intensity.

$@$ ERSpublications

In 1635 patients with oxygen-dependent ILD, $40 \%$ received benzodiazepines and $43 \%$ received opioids, but the medications were rarely used for breathlessness $(6.4 \%$ and $1.4 \%$ of indications, respectively) even at the end of life https://bit.ly/2KbOen7

Cite this article as: Genberg J, Davies JM, Ahmadi Z, et al. Indications and patterns of use of benzodiazepines and opioids in severe interstitial lung disease: a population-based longitudinal study. ERJ Open Res 2021; 7: 00716-2020 [https://doi.org/10.1183/23120541.00716-2020].

This article has supplementary material available from openres.ersjournals.com

Received: 1 Oct 2020 | Accepted after revision: 4 Dec 2020

Copyright $\odot$ ERS 2021. This article is open access and distributed under the terms of the Creative Commons Attribution Non-Commercial Licence 4.0. 


\section{Introduction}

Interstitial lung disease (ILD) is a growing group of disorders that cause fibrosis of the alveoli, distal airways and septal interstitium of the lungs [1]. ILD is associated with poor survival and had $\sim 50 \%$ increase in mortality globally between 2007 and 2017 [2]. The clinical features include worsening symptoms, declining activity and fitness, and, in advanced disease, respiratory distress at rest $[3,4]$. Breathlessness is the predominant symptom in severe ILD, and is associated with deteriorating health-related quality of life and increased risk of hospital admission and premature death [5-9]. As the disease progresses, disabling breathlessness becomes persistent despite optimal treatment of the underlying disease(s), i.e. chronic breathlessness [10].

Evidence supports the use of systemic (non-nebulised) morphine for the symptomatic relief of chronic breathlessness in patients with a variety of diseases [11]. Significant reductions of breathlessness intensity have been shown for low-dose, systemic morphine [12-14]. The risk of respiratory depression is low when treated with regular, low-dose morphine, and no association between opioids used for breathlessness and increased hospital admissions has been reported [14, 15]. Neither low-dose nor high-dose opioids have shown association with increased mortality in ILD [14].

Benzodiazepines (BDZs) are used to treat anxiety and are sometimes prescribed for the relief of breathlessness, but the evidence on effectiveness is insufficient [16].

Physicians may be reluctant to prescribe regular, low-dose morphine due to fear of adverse effects, insufficient knowledge of initiation and titration, and a lack of current treatment guidelines [17-19]. No study has evaluated the indications for prescribed opioids and BDZs for patients with ILD. A comparison of prescribing practice in BDZs (lack of evidence for effectiveness in breathlessness) and opioids (evidence for effectiveness in breathlessness) is of interest.

The aim of this study was to evaluate the indications, medications used and temporal patterns of opioid and BDZ prescriptions in people with oxygen-dependent ILD.

\section{Material and methods}

\section{Design and population}

This was an observational, population-based, longitudinal cohort study of prescriptions for BDZs and opioids received by patients aged $\geqslant 18$ years, starting long-term oxygen therapy (LTOT) for physician-diagnosed ILD between October 1, 2005 and December 31, 2014, in the Swedish National Registry for Respiratory Failure (Swedevox) [20]. If a patient started LTOT more than once during the study period, only the most recent LTOT episode was included. The design is similar to a previous study using the Swedevox registry database to investigate indications for opioids in patients with oxygen-dependent chronic obstructive pulmonary disease (COPD) [21].

\section{Assessments}

The following patient-level data were collected from Swedevox at the start of LTOT (baseline) [20]: age, sex, forced expiratory volume in $1 \mathrm{~s}\left(\mathrm{FEV}_{1}\right) \%$ predicted, vital capacity $(\mathrm{VC}) \%$ predicted, $\mathrm{FEV}_{1} / \mathrm{VC}$, and arterial oxygen tension $\left(P_{\mathrm{aO}_{2}}\right)$ and arterial carbon dioxide tension $\left(P_{\mathrm{aCO}_{2}}\right)$ while breathing air and oxygen. The data in Swedevox, including the ILD diagnosis, spirometry and blood gases, were recently validated with high concordance with medical records [22].

Data on dispensed drug prescriptions were obtained from the Swedish Prescribed Drug Register, which includes all dispensed prescriptions during outpatient care nationwide. A random sample of the cohort's dispensed BDZ (random sample of $n=2000)$ and opioid $(n=2000)$ prescriptions was taken from the time period between 6 months prior to starting LTOT and end of follow-up (the earliest of either date of death or study end). Prescriptions from 6 months before the patients started LTOT were included to capture drugs that may have been prescribed earlier but used during the study period. Data on type of BDZ or opioid medication, defined daily doses, dosing type (as-needed or regular dosing) and the free-text indication(s) were obtained from the registry. Indications were not mutually exclusive and were categorised as breathlessness, pain, anxiety, other or missing.

\section{Ethical considerations}

The study was approved by the Lund University (Lund, Sweden) Research Ethics Committee (2016/846) and the Swedish National Board of Health and Welfare. Individual patient consent was not required as the study used de-identified data aggregated nationally.

\section{Statistical analyses}

Baseline patient characteristics were summarised for all ILD patients receiving BDZ or opioid prescriptions during the study period, and for patients with prescriptions in the random sample, separately for those with known and unknown indications. 
To understand differences in recording practices, the proportion of known and unknown indications was described by the year the prescription was filled and how the product was prescribed: 1) "dose" prescriptions, for patients who typically receive drugs organised into daily doses to assist them in taking the correct amounts or patients receiving one-off prescriptions, and 2) all other "regular" prescriptions.

Prescriptions were evaluated in two steps: 1) all dispensed prescriptions in the random sample during the study period were analysed to describe the type of prescribed medication, defined daily doses and dosing schedule (regular, as-needed or both), and 2) indications (breathlessness, pain, anxiety, other or missing) were described for all dispensed prescriptions in the random sample, excluding "dose" prescriptions before 2012, as this type of prescription did not include indication text in the Prescribed Drug Register before that date. Indications were described for $\mathrm{BDZ}$ and opioid prescriptions overall, and separately for two time periods: 6 months before LTOT start and the last 6 months of LTOT. Variations in indications over the last 12 months of life were described for prescriptions filled by patients who died while receiving LTOT. Prescriptions could contain more than one indication and could be for regular dosing and "as-needed" dosing simultaneously.

We used mean and standard deviation to describe normally distributed variables, median and interquartile range (IQR) for variables with skewed distributions, and frequency and percentage for categorical data. The Chi-squared test was used to test for differences between groups; statistical significance was set at $\mathrm{p}<0.05$. Analyses were performed using Stata version 14.2 (StataCorp, College Station, TX, USA).

\section{Results}

A total of 1635 patients with fibrotic ILD started LTOT between October 1, 2005 and December 31, 2014. Opioids were received by 710 (43.4\%) and BDZs by 651 (39.8\%) patients during the study period, and 373 (22.8\%) patients received both opioids and BDZs.

Patients who used BDZs were aged $76.2 \pm 8.8$ years and $41.9 \%$ were female; patients who used opioids were aged $75.7 \pm 9.5$ years and $44.1 \%$ were female (table 1 ).

The random samples of 2000 opioid and $2000 \mathrm{BDZ}$ prescriptions were filled by a total of 744 patients, of whom 470 patients filled opioid prescriptions, 486 filled BDZ prescriptions, and 212 patients in the random sample filled both BDZ and opioid prescriptions.

Indications were known in $52.1 \%$ of BDZ prescriptions and $54.4 \%$ of opioid prescriptions included in the random sample. Missing indications were largely due to the fact that indications were not registered for "dose" prescriptions before 2012; 72.3\% of "dose" prescriptions had unknown indications compared with $27.4 \%$ of "regular" prescriptions $(\mathrm{p}<0.001)$. Characteristics were similar between patients with unknown and known indications (supplemental table S2).

\section{TABLE 1 Characteristics of oxygen-dependent interstitial lung disease patients}

\begin{tabular}{|c|c|c|c|}
\hline & All patients & Patients prescribed benzodiazepines & Patients prescribed opioids \\
\hline Patients & 1635 & 651 & 710 \\
\hline Age years & $76.3 \pm 9.0$ & $76.2 \pm 8.8$ & $75.7 \pm 9.5$ \\
\hline Female & $606(37.1)$ & 273 (41.9) & $313(44.1)$ \\
\hline $\mathrm{FEV}_{1} \%$ pred & $68.4 \pm 24.4$ & $67.1 \pm 21.8$ & $66.5 \pm 23.3$ \\
\hline Missing & $689(42.1)$ & $269(41.3)$ & $308(43.4)$ \\
\hline VC \% pred & $57.7 \pm 23.0$ & $56.1 \pm 19.8$ & $57.1 \pm 21.2$ \\
\hline Missing & $694(42.4)$ & $269(41.3)$ & 309 (43.5) \\
\hline $\mathrm{FEV}_{1} / \mathrm{VC}$ & $0.8 \pm 0.4$ & $0.9 \pm 0.6$ & $0.8 \pm 0.1$ \\
\hline Missing & $648(39.6)$ & 256 (39.3) & $291(41.0)$ \\
\hline$P_{\mathrm{aO}_{2}}$ air $\mathrm{kPa}$ & $6.6 \pm 1.0$ & $6.7 \pm 1.0$ & $6.6 \pm 1.0$ \\
\hline Missing & $367(22.4)$ & $150(23.0)$ & $162(22.8)$ \\
\hline$P_{\mathrm{acO}_{2}}$ air $\mathrm{kPa}$ & $5.1 \pm 1.0$ & $5.1 \pm 0.9$ & $5.2 \pm 0.9$ \\
\hline Missing & $375(22.9)$ & $152(23.4)$ & $164(23.1)$ \\
\hline Follow-up days & 228 (82-512) & $280(111-570)$ & $304.5(118-646)$ \\
\hline
\end{tabular}


Types of BDZs and opioids

The most frequently dispensed BDZ was oxazepam (85.6\%) and BDZ prescriptions were most commonly prescribed as "as-needed" doses (44.4\%), as shown in table 2. For opioids, the most common medication was oxycodone (28.7\%) and opioids were most frequently prescribed for regular dosing $(39.9 \%)$.

\section{Indications and temporal patterns}

The predominant indication for BDZs was anxiety (96.9\%) and for opioids was pain (94.8\%) over the study period. Indications by drug type are shown in table 3 . The main opioid prescribed for breathlessness was morphine.

Indications for breathlessness remained low for BDZs throughout follow-up, increasing from $0.5 \%$ in the 6 months before starting LTOT to $2.2 \%$ in the last 6 months of LTOT ( $p=0.13$ ). For opioids, indications for breathlessness were low, but there was a small but significant increase from $1.4 \%$ in the 6 months before starting LTOT to $9.6 \%$ in the last 6 months of LTOT $(\mathrm{p}<0.001)$ (table 4$)$

Figure 1 shows the trend for indications in the last 12 months of life for patients who died while receiving LTOT (see supplementary table S2 for the data). The stated indications for BDZ prescriptions remained stable over the last 12 months of life, with indications for anxiety most common (96.5\%). For opioid prescriptions, indications for pain were most common $(94.2 \%)$, but there was a small but statistically significant increase in indications for breathlessness, increasing from $2.5 \%$ (12-10 months before death) to $10.2 \%$ in the last 3 months of life ( $\mathrm{p}=0.048)$.

Over time, the proportion of patients who were dispensed the medications declined slightly. Between 2007-2009 and 2012-2014, the proportion of patients using BDZs decreased from 42.2\% to $37.2 \%$ $(\mathrm{p}=0.096)$ and for opioids from $46.6 \%$ to $38.4 \%(\mathrm{p}=0.006)$. However, there were no time trends for treatment during the last 6 months of LTOT, neither for BDZs (38.2\% versus $35.4 \%$; $=0.35$ ) nor for opioids (34.0\% versus $32.8 \%$; $\mathrm{p}=0.68)$.

\section{Discussion}

In patients with severe oxygen-dependent ILD, breathlessness as an indication for prescription was rare overall at $1.4 \%$ for $\mathrm{BDZ}$ prescriptions and $6.4 \%$ for opioid prescriptions. Indications for breathlessness were low but increased slightly over the LTOT treatment period for opioids, and remained low and stable throughout the treatment period for BDZs. These findings suggest that patients with severe oxygen-dependent ILD, many of whom are likely to suffer chronic respiratory symptoms [5], are rarely treated with these medications even at the end of life.

Chronic breathlessness is very common in severe ILD, including at the end of life $[7,9,14]$. Palliative and end-of-life care is of crucial importance for these severely ill patients with a high symptom burden.

\begin{tabular}{|c|c|c|}
\hline & BDZs & Opioids \\
\hline Prescriptions (random sample) & 2000 & 2000 \\
\hline DDDs per prescriptions & $33.0 \pm 37.4$ & $19.7 \pm 28.2$ \\
\hline Missing & $0(0.0)$ & $18(0.9)$ \\
\hline \multicolumn{3}{|l|}{ BDZ } \\
\hline Oxazepam & $1712(85.6)$ & \\
\hline Diazepam & $139(7.0)$ & \\
\hline Alprazolam & $123(6.2)$ & \\
\hline Other & 26 (1.3) & \\
\hline \multicolumn{3}{|l|}{ Opioid } \\
\hline Codeine & & 269 (13.5) \\
\hline Dextropropoxyphene & & $97(4.9)$ \\
\hline Fentanyl & & $132(6.6)$ \\
\hline Morphine & & $440(22.0)$ \\
\hline Oxycodone & & $573(28.7)$ \\
\hline Tramadol & & $384(19.2)$ \\
\hline Other & & 105 (5.3) \\
\hline
\end{tabular}

Data presented as $n$, mean \pm SD or $n(\%)$; percentages do not sum to 100 due to rounding. DDDs: defined daily doses. 


\begin{tabular}{|c|c|c|c|c|}
\hline & Pain & Breathlessness & Anxiety & Other \\
\hline \multicolumn{5}{|l|}{ Opioid } \\
\hline Codeine & 149 (98.7) & $0(0.0)$ & $0(0.0)$ & $7(4.6)$ \\
\hline Morphine & $225(83.6)$ & 52 (19.3) & $16(5.9)$ & $19(7.1)$ \\
\hline Dextropropoxyphene & 35 (100.0) & $0(0.0)$ & $0(0.0)$ & $0(0.0)$ \\
\hline Fentanyl & 72 (97.3) & $3(4.1)$ & $0(0.0)$ & $0(0.0)$ \\
\hline Oxycodone & $288(97.3)$ & $12(4.1)$ & $1(0.3)$ & $2(0.7)$ \\
\hline Tramadol & $196(100.0)$ & $0(0.0)$ & $0(0.0)$ & $0(0.0)$ \\
\hline Other & 65 (98.5) & $3(4.5)$ & $0(0.0)$ & $0(0.0)$ \\
\hline Total & 1030 & 70 & 17 & 28 \\
\hline p-value & $<0.001$ & $<0.001$ & $<0.001$ & $<0.001$ \\
\hline \multicolumn{5}{|l|}{ BDZ } \\
\hline Alprazolam & $0(0.0)$ & $0(0.0)$ & $76(100.0)$ & $2(2.6)$ \\
\hline Diazepam & $1(1.2)$ & $0(0.0)$ & $68(84.0)$ & 16 (19.8) \\
\hline Oxazepam & $1(0.1)$ & 15 (1.7) & 862 (97.8) & 34 (3.9) \\
\hline Other & $0(0.0)$ & $0(0.0)$ & $3(100.0)$ & 1 (33.3) \\
\hline Total & 2 & 15 & 1009 & 53 \\
\hline$p$-value & 0.17 & 0.43 & $<0.001$ & $<0.001$ \\
\hline
\end{tabular}

Data are presented as $n(\%)$ or $n$, unless otherwise stated; percentages do not sum to 100 as multiple indications could be stated.

A previous study found lower use of structured symptom assessments for end-of-life patients with ILD compared with people diagnosed with lung cancer [9], which may lead to poorer recognition and fewer attempts to control symptoms. In line with the present findings, opioids are also rarely prescribed for breathlessness in COPD in Sweden, where the incidence of opioids was only $4 \%$ in the last 6 months of life [21]. Similar findings were seen in COPD patients at a hospital in France, where, despite having chronic breathlessness, none of the included patients received opioids [23].

Our finding that indications for breathlessness are more common for opioid than BDZ prescriptions potentially reflects, at least partly, the availability of evidence supporting the use of opioids in the treatment of breathlessness (mainly extrapolated from patients with COPD and other severe illness) and the corresponding lack of evidence supporting the use of BDZs for breathlessness $[12,13,16,24]$. The

TABLE 4 Indications for random samples of benzodiazepine (BDZ) and opioid prescriptions in oxygen-dependent interstitial lung disease

\begin{tabular}{|c|c|c|c|c|}
\hline & Overall & 6 months before starting LTOT & Last 6 months of LTOT & p-value \\
\hline Prescriptions & 3039 & 489 & 860 & \\
\hline \multicolumn{5}{|l|}{ BDZs } \\
\hline \multicolumn{5}{|l|}{ Known indication } \\
\hline Pain & $2(0.2)$ & $1(0.5)$ & $0(0.0)$ & 0.127 \\
\hline Breathlessness & $15(1.4)$ & $1(0.5)$ & $10(2.2)$ & 0.127 \\
\hline Anxiety & 1009 (96.9) & 193 (96.5) & $454(97.4)$ & 0.511 \\
\hline Other & $53(5.1)$ & $12(6.0)$ & $29(6.2)$ & 0.913 \\
\hline Unknown indication & $387(27.1)$ & $76(27.5)$ & $167(26.4)$ & 0.718 \\
\hline \multicolumn{5}{|l|}{ Opioids } \\
\hline \multicolumn{5}{|l|}{ Known indication } \\
\hline Pain & 1030 (94.8) & 284 (98.3) & $364(92.4)$ & $0.001 *$ \\
\hline Breathlessness & $70(6.4)$ & $4(1.4)$ & $38(9.6)$ & $<0.001 *$ \\
\hline Anxiety & $17(1.6)$ & $0(0.0)$ & $12(3.1)$ & $0.003^{*}$ \\
\hline Other & $28(2.6)$ & $5(1.7)$ & $12(3.1)$ & 0.276 \\
\hline Unknown indication & 524 (32.5) & $102(26.1)$ & $211(34.9)$ & $0.004^{*}$ \\
\hline \multicolumn{5}{|c|}{$\begin{array}{l}\text { Data are presented as } n \text { or } n(\%) \text {, unless otherwise stated. LTOT: long-term oxygen therapy. Data for } \\
\text { "dose" prescriptions before } 2012 \text { were excluded as they lacked data on indications in the Prescribed Drug } \\
\text { Register. *: } p<0.05 \text { (Chi-squared test). }\end{array}$} \\
\hline
\end{tabular}



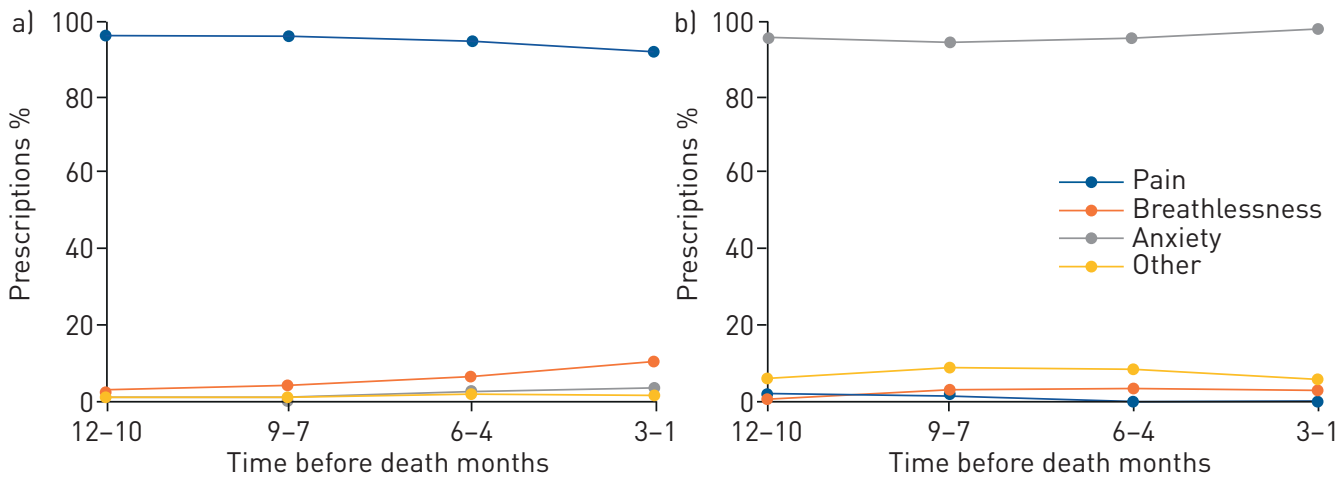

FIGURE 1 Trends for indications in random samples of a) 552 opioid and b) 594 benzodiazepine prescriptions for deceased patients with oxygen-dependent interstitial lung disease (known indications in the last 12 months of life).

number of opioid indications for breathlessness remained low, suggesting that uncertainty around safety and effectiveness could be a barrier to greater use of opioids. Lack of indications for breathlessness in opioid prescriptions could also be due to breathlessness being overlooked as a therapeutic target. In our sample, BDZs were prescribed for breathlessness in a small number of cases, despite the lack of evidence for effectiveness. Possible explanations for this include prescribing BDZs for breathlessness as a second choice following unsuccessful use of opioids or prescribing for anxiety in the presence of breathlessness as these symptoms commonly occur together [25-27].

BDZs were mostly prescribed "as-needed", reflecting their main indication for anxiety. Opioids were mostly prescribed for regular dosing, reflecting their main indication for (chronic) pain.

A strength of this study is the use of national registry (Swedevox) data with nationwide coverage yielding high external validity to patients in Sweden and similar high-income settings [20]. A further strength is that the study evaluated a large random sample of dispensed prescriptions longitudinally that is likely to be representative of all dispensed prescriptions for the cohort. A limitation was missing data on some of the clinical characteristics, which reflects the nature of the clinical register data used for this study. Data from the patients' medical records were not available and therefore could not be used to cross-validate the free-text indications. It is possible that the indications for breathlessness were underestimated as the medications may have been prescribed for breathlessness in conjunction with another symptom (with only the latter stated as an indication), e.g. in BDZs prescribed for anxiety related to breathlessness, and in patients with concurrent pain and breathlessness.

The findings in this study form the baseline for future research to evaluate temporal trends in prescribing both opioids and BDZs to patients with ILD. The results indicate that chronic respiratory symptoms may be undertreated in patients with oxygen-dependent ILD, which warrants further evaluation. The results may also contribute to identify possible improvements for clinicians regarding treatment in severe ILD to improve the overall wellbeing of patients.

The present findings have several important implications. It would be desirable that the high prevalence of prescribed tramadol be reduced for this seriously ill and elderly population as it is not recommended due to side-effects (especially from drug-drug interactions) that may pose a danger. However, tramadol prescription may have declined since the end of the study period in 2014. Trends in prescription for breathlessness over the years could not be evaluated due to the low number of prescriptions for breathlessness overall. The finding that many prescriptions lacked an indication indicates the need for clinicians to improve the stated indications. In order to introduce evidence-based opioid therapy for breathlessness in severe ILD, more research (including randomised controlled trials of symptomatic treatment) is needed to inform opioid treatment efficacy and safety.

In conclusion, in oxygen-dependent ILD, BDZs and opioids are rarely prescribed for breathlessness even in the last months of life in a population with a high prevalence of chronic breathlessness that often worsens as death approaches.

Acknowledgements: We thank all the nurses and staff that entered the data in the registry and cared for the patients.

Data availability: De-identified data underlying the findings are available upon reasonable request from the corresponding author. 
Author contributions: Conception, planning and acquisition of data: M. Ekström. Study design: J. Genberg, J.M. Davies, M.J. Johnson, D. Currow and M. Ekström. Statistical analysis: J.M. Davies. Interpretation of data: all authors. First draft: J. Genberg, J.M. Davies and M. Ekström. Revisions and acceptance of final version: all authors.

Support statement: M. Ekström was supported by an unrestricted grant from the Swedish Society for Medical Research and Swedish Research Council (2019-02081). Funding information for this article has been deposited with the Crossref Funder Registry.

Conflict of interest: None declared.

\section{References}

1 Cottin V, Hirani NA, Hotchkin DL, et al. Presentation, diagnosis and clinical course of the spectrum of progressive-fibrosing interstitial lung diseases. Eur Respir Rev 2018; 27: 180076.

2 GBD 2017 Mortality Collaborators. Global, regional, and national age-sex-specific mortality and life expectancy, 1950-2017: a systematic analysis for the Global Burden of Disease Study 2017. Lancet 2018; 392: 1684-1735.

3 Kolb M, Vasakova M. The natural history of progressive fibrosing interstitial lung diseases. Respir Res 2019; 20: 57.

4 Swigris JJ, Brown KK, Abdulqawi R, et al. Patients' perceptions and patient-reported outcomes in progressive-fibrosing interstitial lung diseases. Eur Respir Rev 2018; 27: 180075.

5 Carvajalino S, Reigada C, Johnson MJ, et al. Symptom prevalence of patients with fibrotic interstitial lung disease: a systematic literature review. BMC Pulm Med 2018; 18: 78.

6 Collard HR, Pantilat SZ. Dyspnea in interstitial lung disease. Curr Opin Support Palliat Care 2008; 2: 100-104.

7 Bajwah S, Higginson IJ, Ross JR, et al. The palliative care needs for fibrotic interstitial lung disease: a qualitative study of patients, informal caregivers and health professionals. Palliat Med 2013; 27: 869-876.

8 Swigris JJ, Kuschner WG, Jacobs SS, et al. Health-related quality of life in patients with idiopathic pulmonary fibrosis: a systematic review. Thorax 2005; 60: 588-594.

9 Ahmadi Z, Wysham NG, Lundstrom S, et al. End-of-life care in oxygen-dependent ILD compared with lung cancer: a national population-based study. Thorax 2016; 71: 510-516.

10 Johnson MJ, Yorke J, Hansen-Flaschen J, et al. Towards an expert consensus to delineate a clinical syndrome of chronic breathlessness. Eur Respir J 2017; 49: 1602277.

11 Parshall MB, Schwartzstein RM, Adams L, et al. An official American Thoracic Society statement: update on the mechanisms, assessment, and management of dyspnea. Am J Respir Crit Care Med 2012; 185: 435-452.

12 Abernethy AP, Currow DC, Frith P, et al. Randomised, double blind, placebo controlled crossover trial of sustained release morphine for the management of refractory dyspnoea. BMJ 2003; 327: 523-526.

13 Matsuda Y, Maeda I, Tachibana K, et al. Low-dose morphine for dyspnea in terminally ill patients with idiopathic interstitial pneumonias. J Palliat Med 2017; 20: 879-883.

14 Bajwah S, Davies JM, Tanash H, et al. Safety of benzodiazepines and opioids in interstitial lung disease: a national prospective study. Eur Respir J 2018; 52: 1801278.

15 Portenoy RK, Sibirceva U, Smout R, et al. Opioid use and survival at the end of life: a survey of a hospice population. J Pain Symptom Manage 2006; 32: 532-540.

16 Simon ST, Higginson IJ, Booth S, et al. Benzodiazepines for the relief of breathlessness in advanced malignant and non-malignant diseases in adults. Cochrane Database Syst Rev 2016; 10: CD007354.

17 Ahmadi Z, Sandberg J, Shannon-Honson A, et al. Is chronic breathlessness less recognised and treated compared with chronic pain? A case-based randomised controlled trial. Eur Respir J 2018; 52: 1800887.

18 Rocker G, Young J, Donahue M, et al. Perspectives of patients, family caregivers and physicians about the use of opioids for refractory dyspnea in advanced chronic obstructive pulmonary disease. CMAJ 2012; 184: E497-E504.

19 Young J, Donahue M, Farquhar M, et al. Using opioids to treat dyspnea in advanced COPD: attitudes and experiences of family physicians and respiratory therapists. Can Fam Physician 2012; 58: E401-E407.

20 Ekstrom M, Ahmadi Z, Larsson H, et al. A nationwide structure for valid long-term oxygen therapy: 29-year prospective data in Sweden. Int J Chron Obstruct Pulmon Dis 2017; 12: 3159-3169.

21 Ahmadi Z, Bernelid E, Currow DC, et al. Prescription of opioids for breathlessness in end-stage COPD: a national population-based study. Int J Chron Obstruct Pulmon Dis 2016; 11: 2651-2657.

22 Ekström M, Albrecht D, Andersson S, et al. Validation of Swedevox registry of continuous positive airway pressure, long-term mechanical ventilator and long-term oxygen therapy. ERJ Open Res 2021; 7: 00340-2020.

23 Carette $\mathrm{H}$, Zysman M, Morelot-Panzini $\mathrm{C}$, et al. Prevalence and management of chronic breathlessness in COPD in a tertiary care center. BMC Pulm Med 2019; 19: 95.

24 Takeyasu M, Miyamoto A, Kato D, et al. Continuous intravenous morphine infusion for severe dyspnea in terminally ill interstitial pneumonia patients. Intern Med 2016; 55: 725-729.

25 Ekström MP, Abernethy AP, Currow DC. The management of chronic breathlessness in patients with advanced and terminal illness. BMJ 2015; 349: g7617.

26 Janson C, Bjornsson E, Hetta J, et al. Anxiety and depression in relation to respiratory symptoms and asthma. Am J Respir Crit Care Med 1994; 149: 930-934.

27 Dales RE, Spitzer WO, Schechter MT, et al. The influence of psychological status on respiratory symptom reporting. Am Rev Respir Dis 1989; 139: 1459-1463. 